\title{
Betulinic acid enhances TGF- $\beta$ signaling by altering TGF- $\beta$ receptors partitioning between lipid-raft/caveolae and non- caveolae membrane microdomains in mink lung epithelial cells
}

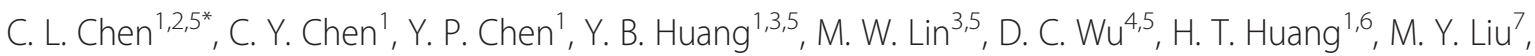
H. W. Chang ${ }^{1}$, Y. C. Kao ${ }^{1}$ and P. H. Yang ${ }^{1}$

\begin{abstract}
Background: TGF- $\beta$ is a key modulator in the regulation of cell proliferation and migration, and is also involved in the process of cancer development and progression. Previous studies have indicated that TGF- $\beta$ responsiveness is determined by TGF- $\beta$ receptor partitioning between lipid raft/caveolae-mediated and clathrin-mediated endocytosis. Lipid raft/caveolae-mediated endocytosis facilitates TGF- $\beta$ degradation and thus suppressing TGF- $\beta$ responsiveness. By contrast, clathrin-mediated endocytosis results in Smad2/3-dependent endosomal signaling, thereby promoting TGF- $\beta$ responsiveness. Because betulinic acid shares a similar chemical structure with cholesterol and has been reported to insert into the plasma membrane, we speculate that betulinic acid changes the fluidity of the plasma membrane and modulates the signaling pathway associated with membrane microdomains. We propose that betulinic acid modulates TGF- $\beta$ responsiveness by changing the partitioning of TGF- $\beta$ receptor between lipid-raft/caveolae and non-caveolae microdomain on plasma membrane.

Methods: We employed sucrose-density gradient ultracentrifugation and confocal microscopy to determine membrane localization of TGF- $\beta$ receptors and used a luciferase assay to examine the effects of betulinic acid in TGF- $\beta$-stimulated promoter activation. In addition, we perform western blotting to test TGF- $\beta$-induced Smad2 phosphorylation and fibronectin production.

Results and conclusions: Betulinic acid induces translocation of TGF- $\beta$ receptors from lipid raft/caveolae to non-caveolae microdomains without changing total level of TGF- $\beta$ receptors. The betulinic acid-induced TGF- $\beta$ receptors translocation is rapid and correlate with the TGF- $\beta$-induced PAl-1 reporter gene activation and growth inhibition in Mv1Lu cells.
\end{abstract}

Keywords: Betulinic acid, Lipid-raft, Caveolae, TGF-beta

\footnotetext{
* Correspondence: chunlinchen@mail.nsysu.edu.tw

'Department of Biological Science, National Sun Yat-sen University,

Kaohsiung 804Taiwan, ROC

${ }^{2}$ Doctoral Degree Program in Marine Biotechnology, National Sun Yat-sen

University and Academia Sinica, Kaohsiung 804Taiwan, ROC

Full list of author information is available at the end of the article
} 


\section{Background}

Betulinic acid (BetA) [1] is a luphane-type pentacyclic triterpenoid (Fig. 1) of plant origin that is wildly distributed in the outer bark of various tree species (eg, white-barked birch trees). BetA exhibits diverse biological activities, and antiviral, antibacterial, antioxidant, anti-inflammatory, antifibrotic, and anticancer properties [2,3]. Antitumorigenesis is one of the most promising functions of BetA. Previous reports have indicated that BetA induces apoptosis in colorectal (DLD-1), breast (MCF7), prostate (PC-3), and lung (A549) cancer cells via the mitochondrial pathway [4-6]. In addition, past studies have reported that BetA-induced apoptosis is not associated with the activation of ligand/receptor systems such as CD95, and does not involve p53 [1]. In BetA-induced apoptosis, the perturbation of mitochondrial function (eg, loss of mitochondrial permeability transition and the production of reactive oxygen species) precedes other key features of apoptosis such as the activation of the caspase cascade and nuclear fragmentation [7, 8]. Recent studies have indicated that BetA also modulate signaling through members of the TGF- $\beta$ superfamily, which regulates inflammatory and immune responses, cell growth, differentiation, and apoptosis [9, 10]. However, the underlying mechanisms regarding the effects of BetA in TGF- $\beta$ signaling are poorly understood.

TGF- $\beta$ is a family of $25-\mathrm{kDa}$ disulfide-linked dimeric proteins. It has 3 members in mammals (TGF- $\beta_{1}$, TGF- $\beta_{2}$, and TGF- $\beta_{3}$,), which share approximately $70 \%$ of the sequence homology $[11,12]$. TGF- $\beta$ exhibits bifunctional growth regulation; it inhibits the growth of most cell types, including epithelial cells, endothelial cells, and lymphocytes, and stimulates the proliferation of mesenchymal cells such as fibroblasts $[11,12]$. In epithelial cells, TGF- $\beta$ inhibits cell proliferation, induces apoptosis, and mediates differentiation, implying that this signaling pathway engages in tumor-suppressing activities in epithelial tumors $[13,14]$. However, TGF- $\beta$ promotes invasive and metastatic activities in late-stage tumor progression, implying that TGF- $\beta$ can paradoxically play opposing roles in human cancers, and this is seemingly dependent on the cancer stage. In addition to its growth regulatory activities, TGF- $\beta$ exhibits other biological activities, including the regulation of extracellular matrix synthesis, chemotaxis, angiogenesis, and the differentiation of several cell lineages. It has been implicated in numerous pathophysiological processes including wound repair, tissue fibrosis, immunosuppression, and morphogenesis [15]. The primary biological activities of TGF- $\beta$ are mediated by specific cell surface receptors type I and type II (T $\beta$ R-I and T $\beta R$-II, respectively). TGF- $\beta$ exerts its effects on cells by binding to T $\beta R$-II, which induces the recruitment of T $\beta R$ I with the subsequent activation of the receptor complex. Smad2 and Smad3 are the direct substrates of the activated TGF- $\beta$ receptor complex. After stimulation, the Smad complex translocates into the nucleus, where it functions as a member of different transcription factor complexes that regulate the expression of various genes $[12,13,16]$.

We have previously reported that suppressed TGF- $\beta$ responsiveness in the aortic endothelium plays a critical role in the pathogenesis of atherosclerosis in hypercholesterolemic animals $[17,18]$. A high concentration of cholesterol in the culture medium suppresses TGF- $\beta$ responsiveness in cultured cells, including in endothelial cells, by inducing the accumulation of cell-surface TGF- $\beta$-TGF- $\beta$ receptor complexes in the lipid rafts/caveolae of the plasma membrane, facilitating the rapid degradation of these

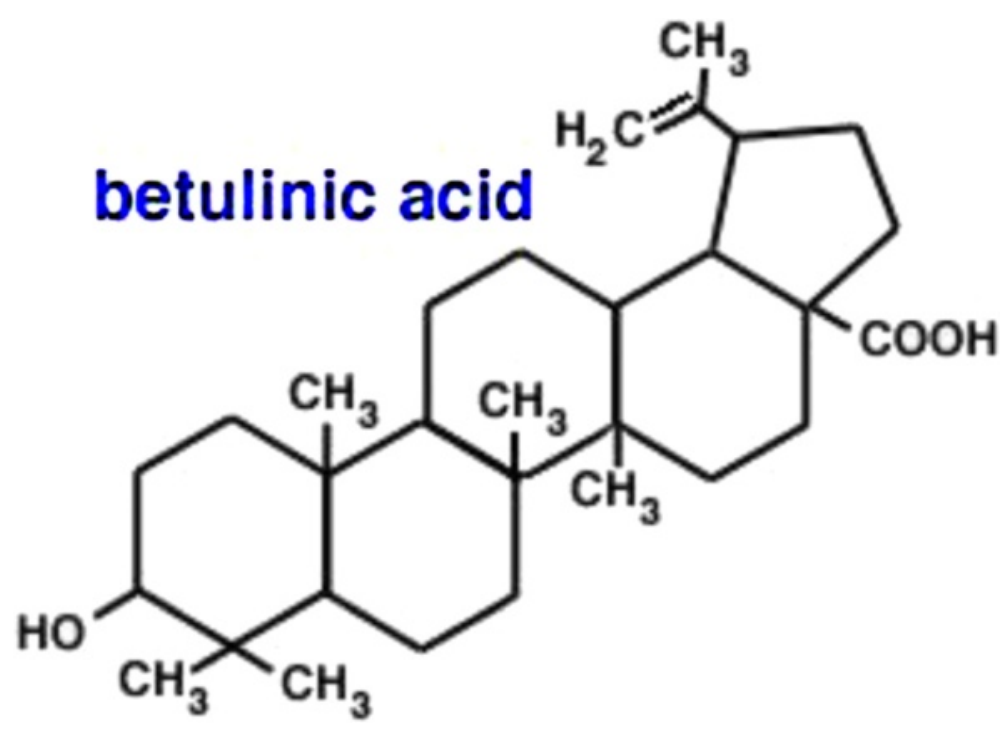

Fig. 1 Structure of betulinic acid (BetA) 
complexes, thereby attenuating TGF- $\beta$-stimulated signaling and related responses [17-19]. This effect of cholesterol is believed to be mediated by the increasing formation or stabilization of the lipid rafts/caveolae, presumably through the direct insertion of cholesterol into the plasma membranes of target cells [17, 18]. Lipid raft/ caveolae are thought to form platforms collecting assemblies of proteins involved in many key cellular functions, including signal transduction, membrane fusion, cytoskeleton organization, lipid sorting, protein trafficking, and the localization and activities of specific membrane channels [20-22]. Because BetA shares a similar chemical structure with cholesterol, and was reported to insert into the plasma membrane [23], it is rational to speculate that BetA changes the fluidity of the plasma membrane and modulates the signaling pathway associated with membrane microdomains. We speculate that BetA modulates TGF- $\beta$ responsiveness by changing the partitioning of the TGF- $\beta$ receptor between the microdomains of the lipid $\mathrm{raft} / \mathrm{caveolae}$ and non-caveolae on the plasma membrane.

Because the TGF- $\beta$ signaling pathway is a key mediator that controls proliferation and inflammation, and BetA has antitumor and anti-inflammation properties, this study investigates the effect of BetA on TGF- $\beta$ signaling, and we attempt to elucidate the mechanisms involved. We found that BetA activates TGF- $\beta$ receptors by moving them from lipid raft to non-raft membrane microdomains, as perceived by the enhancement in TGF- $\beta$-specific reporter gene activity, sucrose gradient fractionation of the plasma membrane, fibronectin protein levels, Smad2/3 phosphorylation, nuclear translocation, and TGF- $\beta$-induced growth inhibition.

\section{Methods}

\section{Materials}

Dulbecco's modified Eagle's medium (DMEM), phenylmethanesulfonyl fluoride (PMSF), Betulinic acid [(3b)-3hydroxy-lup-20(29)-en-28-oic acid], bovine serum albumin (BSA), and peroxidase-conjugated anti-rabbit IgG were obtained from Sigma (St. Louis, MO). The pre-stained protein ladder $(64,49,37,26$, and $20 \mathrm{kDa})$ and fetal calf serum (FCS) was obtained from Invitrogen (Carlsbad, CA). TGF$\beta_{1}$ was purchased from Austral Biologicals (San Ramon, CA). The polyclonal antibodies against early endosome antigen 1 (EEA1), transferrin receptor (TfR), Smad2/3, Caveolin-1, flotillin-2, epidermal growth factor receptor (EGFR), T $\beta R$-I, T $\beta R$-II, and HA-probe were obtained from Santa Cruz (Santa Cruz, CA). The rabbit polyclonal antibody to phospho-Smad2 was purchased from Cell Signaling (Boston, MA).

\section{Cell culture}

Mink lung epithelial (Mv1Lu) cells and Mv1Lu cell stably express plasminogen activator inhibitor-1 (PAI-1) luciferase promoter were kindly provided by Dr. Jung San Huang (Saint Louis University, Saint Louis, MO). The Mv1Lu cells were cultured in DMEM supplemented with 10 \% FCS, $1 \%$ penicillin, and streptomycin ( $\mathrm{pH}$ 7.4). The cells were seeded in tissue culture plates (Falcon, Bedford, MA, USA) and incubated at $37{ }^{\circ} \mathrm{C}$ in a humidified atmosphere of $5 \% \mathrm{CO}_{2}$. The Mv1Lu cells were subcultured twice per week through trypsinization in a $0.25 \%$ trypsin-EDTA solution after washing with $\mathrm{Ca}^{2+}-\mathrm{Mg}^{2+}$-free saline.

\section{Treatment of Mv1Lu cells with TGF- $\beta$ after preincubation with BetA}

The Mv1Lu cells were grown in 12-well plastic plates $\left(4 \times 10^{5}\right.$ cells $/ \mathrm{mL}$ with $1 \mathrm{~mL} /$ well $10 \%$ FCS-DMEM) for $24 \mathrm{~h}$ in a humidified $\mathrm{CO}_{2}$ incubator at $37^{\circ} \mathrm{C}$. Afterward, the medium was replaced with fresh $1 \%$ FCS-DMEM. The cells were subsequently preincubated with BetA for $1 \mathrm{~h}$ at $37{ }^{\circ} \mathrm{C}$. Next, TGF- $\beta$ was added to the medium, and incubation continued for an additional $48 \mathrm{~h}$; the cultures were then washed twice with cold PBS, and harvested for Western blot analysis. To observe Smad2/3 phosphorylation, the cells in the 12-well plastic plates were preincubated with BetA for $1 \mathrm{~h}$ at $37^{\circ} \mathrm{C}$. Afterward, TGF- $\beta 1$ was added to the medium, and incubation continued for $30 \mathrm{~min}$.

\section{Western blot analysis}

The cell lysates of Mv1Lu cells (approximately $50 \mu \mathrm{g}$ protein) were subjected to $10 \%$ SDS-PAGE under reducing conditions, and then electrotransferred to PVDF membranes. After being incubated with $5 \%$ nonfat milk in Tris-buffered saline plus Tween 20 (TBST) $(50 \mathrm{mM}$ Tris-HCl, pH 8.0, $150 \mathrm{mM} \mathrm{NaCl}$, and $0.05 \%$ Tween 20) for $1 \mathrm{~h}$ at room temperature, the membranes were incubated further with specific polyclonal antibodies to T $\beta \mathrm{R}$ I and T $\beta R$-II in TBST/non-fat milk at $4{ }^{\circ} \mathrm{C}$ for $18 \mathrm{~h}$, and washed 3 times with TBST for 10 min each. The bound antibodies were detected using peroxidase-conjugated anti-rabbit IgG and visualized using the ECL system (ImageQuant).

\section{Luciferase activity assay}

The Mv1Lu cells were transiently transfected with fibronectin [24] and collagen [25] luciferase promoter plasmids through electroporation. The cell suspension was mixed with $14 \mu \mathrm{g} / \mathrm{mL}$ of plasmid DNA (and renilla control plasmid) before it was transferred into an electroporation cuvette $(0.4 \mathrm{~cm}$ gap, Bio-Rad, Hercules, $\mathrm{CA})$ and pulsed $(950 \mu \mathrm{F}, 250 \mathrm{~V}$, Gene Pulser II, BioRad). After electroporation, the cells were seeded in 24well cluster plates (Corning), and growth continued for an additional $24 \mathrm{~h}$. The Mv1Lu cells stably express luciferase reporter gene driven by the PAI-1 promoter (MLECs - Clone 32), grown to near confluence on 24- 


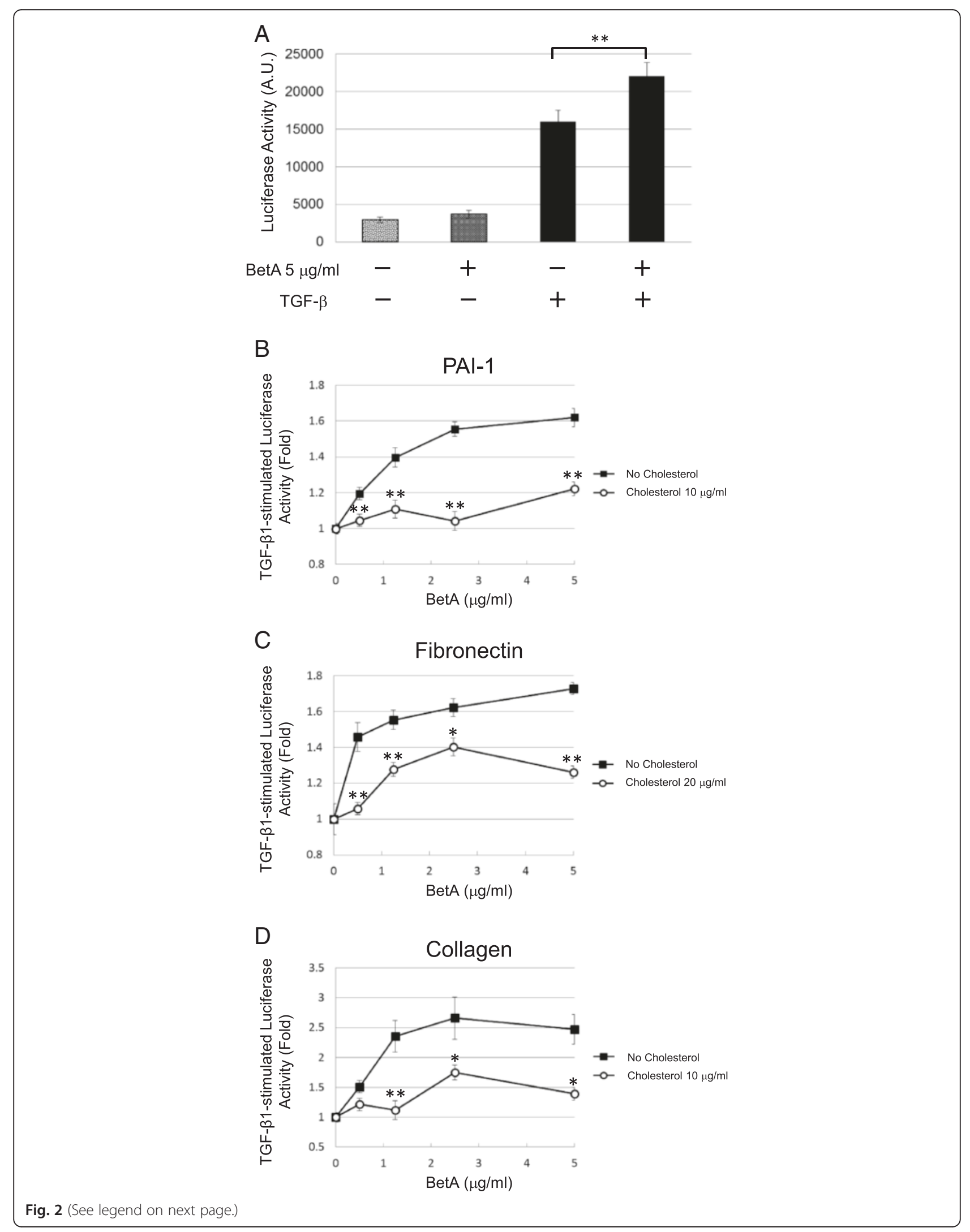


(See figure on previous page.)

Fig. 2 BetA enhances the transcriptional response stimulated by TGF- $\beta$ in Mv1Lu cells. Cells stably expressing the PAl-1 luciferase reporter plasmid exhibited a 6 -fold increase of the luciferase activity after stimulation with 100 pM TGF- $\beta$ and the TGF- $\beta$-stimulated luciferase activity was enhanced by BetA in a concentration-dependent manner (a) and (b). However, the BetA-enhanced TGF- $\beta$-stimulated PAl-1 luciferase activity was diminished in the presence of cholesterol (b). Cells transiently transfected with the fibronectin (c) and collagen (d) luciferase reporter plasmids were treated with 100 pM TGF- $\beta$ and increasing concentrations of BetA and/or cholesterol. BetA also enhanced the TGF- $\beta$-stimulated luciferase activity driven by the promoters of fibronectin $(\mathbf{c})$ and collagen (d). The presence of cholesterol inhibited these BetA-enhanced luciferase activities (b, $\mathbf{c}$, and $\mathbf{d})$. The data bar represents the mean \pm S.D. ${ }^{* *}$ and * indicate the significant different between cells treated with or without BetA (a), or lower than that in cells treated without cholesterol in the same concentration of BetA group (b, $\mathbf{c}$, and $\mathbf{d})\left({ }^{*}: P<0.05,{ }^{* *}: P<0.01\right)$

well plates, were treated with different concentrations of BetA, with or without varying concentrations of cholesterol at $37^{\circ} \mathrm{C}$ for $1 \mathrm{~h}$. The treated cells were further incubated with $50 \mathrm{pM}$ TGF- $\beta 1$ at $37{ }^{\circ} \mathrm{C}$ for $6 \mathrm{~h}$, and lysed in $100 \mu \mathrm{L}$ of a lysis buffer (Promega). The cell lysates (approximately $20 \mu \mathrm{g}$ of protein) were then mixed with a D-luciferin (Gold Biotechnology, St. Louis, $\mathrm{MO}$ ) assay buffer and assayed using the luminometer (Titertek-Berthold, Pforzheim, Germany). The luciferase count was corrected for renilla activity, and a relative increase in corrected luciferase count was calculated versus the controls. A constitutively active ALK-5 (caALK-5) construct was cotransfected at a concentration of $1.2 \mu \mathrm{g} /$ $\mathrm{mL}$ in the indicated experiments.

\section{Immunofluorescent detection of Smad2/3}

Cells were grown on 24-mm round coverglass (Paul Marienfeld). After $1 \mathrm{~h}$ of serum starvation and $1 \mathrm{~h}$ of pretreatment with $5 \mu \mathrm{g} / \mathrm{mL}$ of BetA or the vehicle, cells were stimulated with TGF- $\beta 1(20 \mathrm{pM})$ for $30 \mathrm{~min}$. They were then washed with phosphate buffered saline (PBS) and fixed in cold methanol for $15 \mathrm{~min}$. Afterward, the cells were blocked with $5 \%$ goat serum (Dako) in $1 \%$ BSA/PBS. After incubation with mouse-anti-Smad2/3 (H-2; Santa Cruz Biotechnology) at 1:100 dilution in $1 \%$ $\mathrm{BSA} / \mathrm{PBS}$ for $18 \mathrm{~h}$ at $4{ }^{\circ} \mathrm{C}$, the cells were incubated with donkey anti-mouse-FITC (Gene Tex) at room temperature for $1 \mathrm{~h}$. The coverglass was mounted with a slow-fade gold antifade reagent and DAPI (Invitrogen). Photomicrographs were taken using a Zeiss Axio Observer Z1 microscope equipped with a Photometrics HQ2 camera.

\section{Immunofluorescent confocal microscopy}

The Mv1Lu cells were placed in a 24-mm coverglass and transiently transfected with T $\beta$ R-II-HA plasmid $(0.4 \mu \mathrm{g})$ by using lipofectamin 2000 (Invitrogen) in accordance to the manufacturer protocol. The transfected cells were pretreated with $5 \mu \mathrm{g} / \mathrm{mL}$ of BetA at $37^{\circ} \mathrm{C}$ for $1 \mathrm{~h}$, and then incubated with $100 \mathrm{pM}$ of TGF- $\beta 1$ for $30 \mathrm{~min}$. After TGF$\beta 1$ stimulation, the cells were fixed in methanol at $-20{ }^{\circ} \mathrm{C}$ for $15 \mathrm{~min}$, washed with PBS, and then blocked using $0.2 \%$ gelatin in PBS for $1 \mathrm{~h}$. Cells were incubated overnight at $4{ }^{\circ} \mathrm{C}$ in a humidified chamber with a goat antibody against HA-probe (F-7, Santa Cruz Biotechnology) and a rabbit antibody against caveolin-1 (N-20, Santa Cruz Biotechnology) at 1:100 dilutions. After extensive washing, the cells were incubated with Rhodamine-conjugated donkey anti-goat antibody and FITC-conjugated mouse anti-rabbit antibody at a 1:50 dilution for $1 \mathrm{~h}$. Images were acquired using a Leica TCS SP confocal microscope (Leica Microsystems Ltd., Heidelberg, Germany). The measurements of the colocalization rate were analyzed using a Leica Application Suite.

\section{Separation of lipid-raft and non-lipid raft microdomains of plasma membranes by sucrose density gradient ultracentrifugation}

Sucrose density gradient analysis was performed at $4{ }^{\circ} \mathrm{C}$ as described previously [26]. In brief, cells were grown to near-confluence in $100-\mathrm{mm}$ dishes $\left(5-10 \times 10^{6}\right.$ cells per dish). Cells were incubated with BetA $(5 \mu \mathrm{g} / \mathrm{mL})$ or cholesterol $(25 \mu \mathrm{g} / \mathrm{mL})$ at $37^{\circ} \mathrm{C}$ for $4 \mathrm{~h}$. After 2 washes with ice-cold PBS, the cells were scraped in $0.85 \mathrm{~mL}$ of $500 \mathrm{mM}$ sodium carbonate $(\mathrm{pH} 11)$. Homogenization was performed with 10 strokes of a tightfitting Dounce homogenizer, followed by three 15-s bursts of an ultrasonic disintegrator (Qsonica, Newtown, CT, USA) to disrupt the cell membranes. The homogenates were adjusted to $45 \%$ sucrose by adding $0.85 \mathrm{~mL}$ of $90 \%$

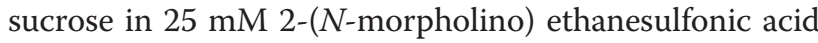
(pH 6.5) and $0.15 \mathrm{M} \mathrm{NaCl}$ (MBS), and placed at the bottom of an ultracentrifuge tube. A discontinuous sucrose gradient was generated by overlaying $1.7 \mathrm{~mL}$ of $35 \%$ sucrose and of $5 \%$ sucrose in MBS on top of the $45 \%$ sucrose solution, and it was subsequently centrifuged at 40000 rpm for $16-20 \mathrm{~h}$ in a P50S2 rotor (Himac, Tokyo, Japan). Ten $0.5-\mathrm{mL}$ fractions were collected from the top of the tube, and a portion of each fraction was analyzed through SDS-PAGE, followed by Western blot analysis using antibodies to T $\beta R I$ (ALK-5), T $\beta$ RII, TfR-1, EEA-1, flotillin-2, EGFR, and caveolin-1. The relative amounts of T $\beta R I$, T $\beta R I I$, TfR- 1 , and caveolin- 1 on the blot were quantified through densitometry. The protein recovery and localization of caveolin-1, flotillin-2, and TfR-1 (fractions 4 to 5 and 8 to 10 , respectively) did not change significantly with any of the treatment protocols

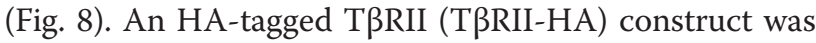




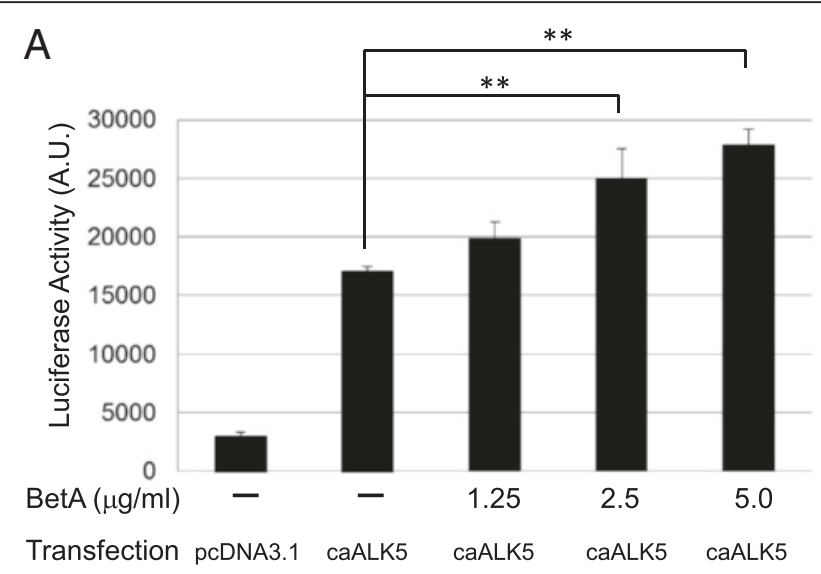

B

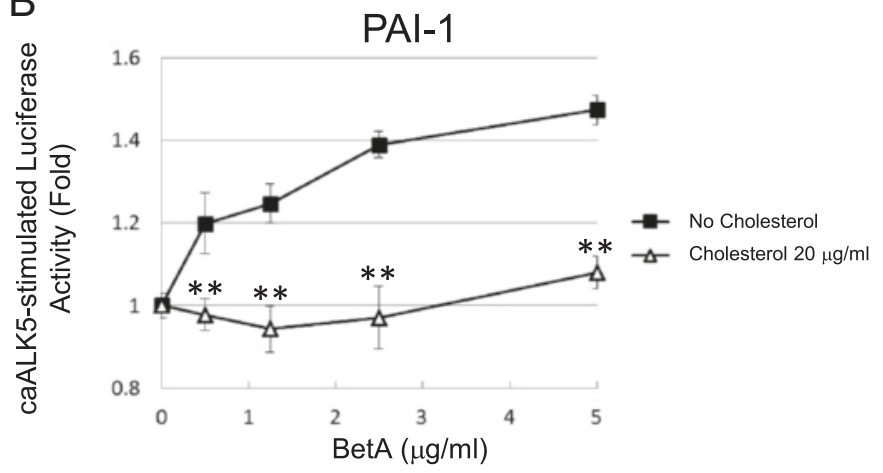

C

Fibronectin
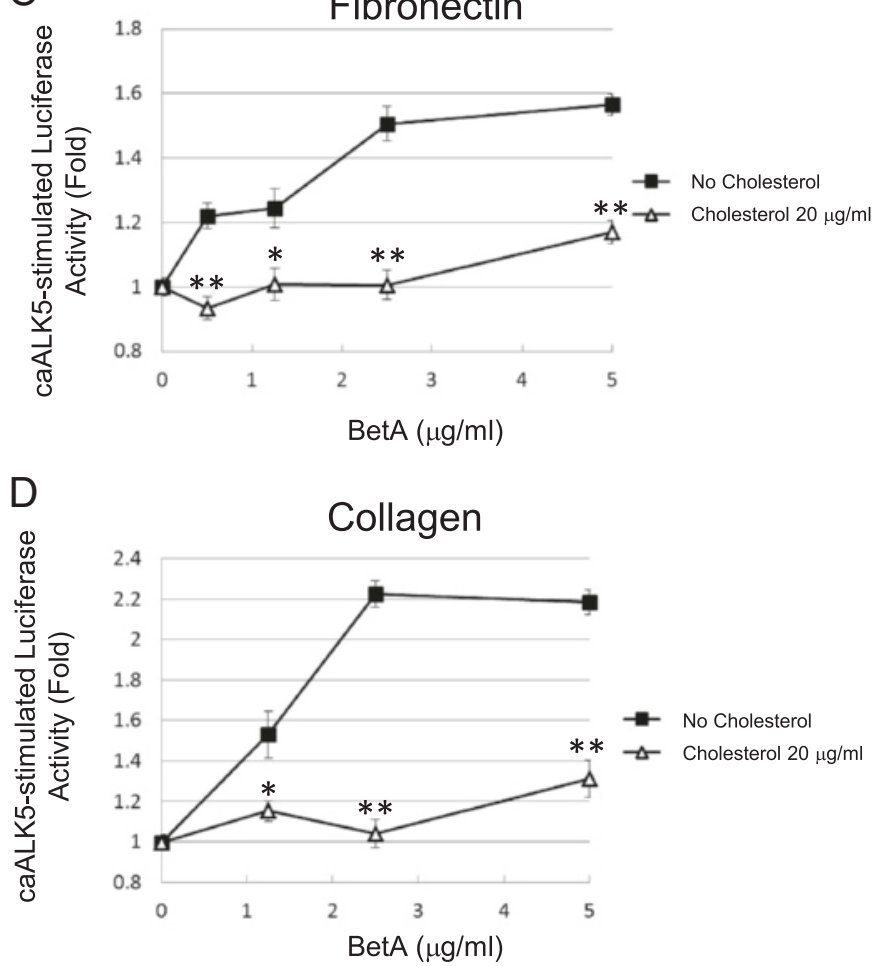

Fig. 3 (See legend on next page.) 
(See figure on previous page.)

Fig. 3 BetA enhances the TGF- $\beta$ response downstream of ALK-5 in Mv1Lu cells. Cells stably expressing the PAl-1 luciferase promoter were transiently transfected with caALK-5 or pcDNA3.1 (as a control). These transfected cells exhibited a potent luciferase activity in the absence of exogenously added TGF- $\beta$. BetA appeared to enhance caALK-5-stimulated PAl-1 ( $\mathbf{a}$ and $\mathbf{b}$ ), fibronectin (c), and collagen (d) promoter luciferase expression in a concentration-dependent manner. Cholesterol treatment suppressed the BetA-enhanced luciferase activity. The data bar represents the mean \pm SD from four different analyses. * and **Significantly higher than that in cells treated without BetA (a) or lower than that in cells treated without cholesterol

$(\mathbf{b}, \mathbf{c}$, and $\mathbf{d})(* * 0<0.05, * *: P<0.01)$

transfected at a concentration of $0.5 \mu \mathrm{g} / \mathrm{mL}$ in the indicated experiments.

\section{MTT viability assay}

The effect of BetA on TGF- $\beta$-induced growth inhibition was determined using an MTT (3-[4,5-dimethylthiazol2-yl]-2,5-diphenyl tetrazoliumbromide) assay. In brief, the cells were plated at $1 \times 10^{4}$ cells per well in $150 \mu \mathrm{L}$ of a culture medium containing $1 \%$ FCS and the desired concentrations of BetA, before they were diluted with the culture media to achieve final concentrations ranging from 0.5 to $5 \mu \mathrm{g} / \mathrm{mL}$. The EtOH concentration remained within the maximum permissible concentration of $0.01 \%$ in both the control and treated samples. After pretreatment with BetA, the cells were treated with TGF- $\beta$, and incubation continued for $30 \mathrm{~h}$ at $37{ }^{\circ} \mathrm{C}$ in a humidified incubator, after which cell viability was determined. Afterward, $50 \mu \mathrm{L}$ of MTT $(4 \mu \mathrm{g} / \mathrm{mL}$ in PBS stock, diluted to a working strength of $1 \mu \mathrm{g} / \mathrm{mL}$ with the media) was added to each well and incubated for $2 \mathrm{~h}$. After the medium was carefully removed, $0.1 \mathrm{~mL}$ of DMSO was added to each well, and the plates were shaken. Absorbance was recorded on a microplate reader, at a wavelength of $570 \mathrm{~nm}$. The effect of BetA on

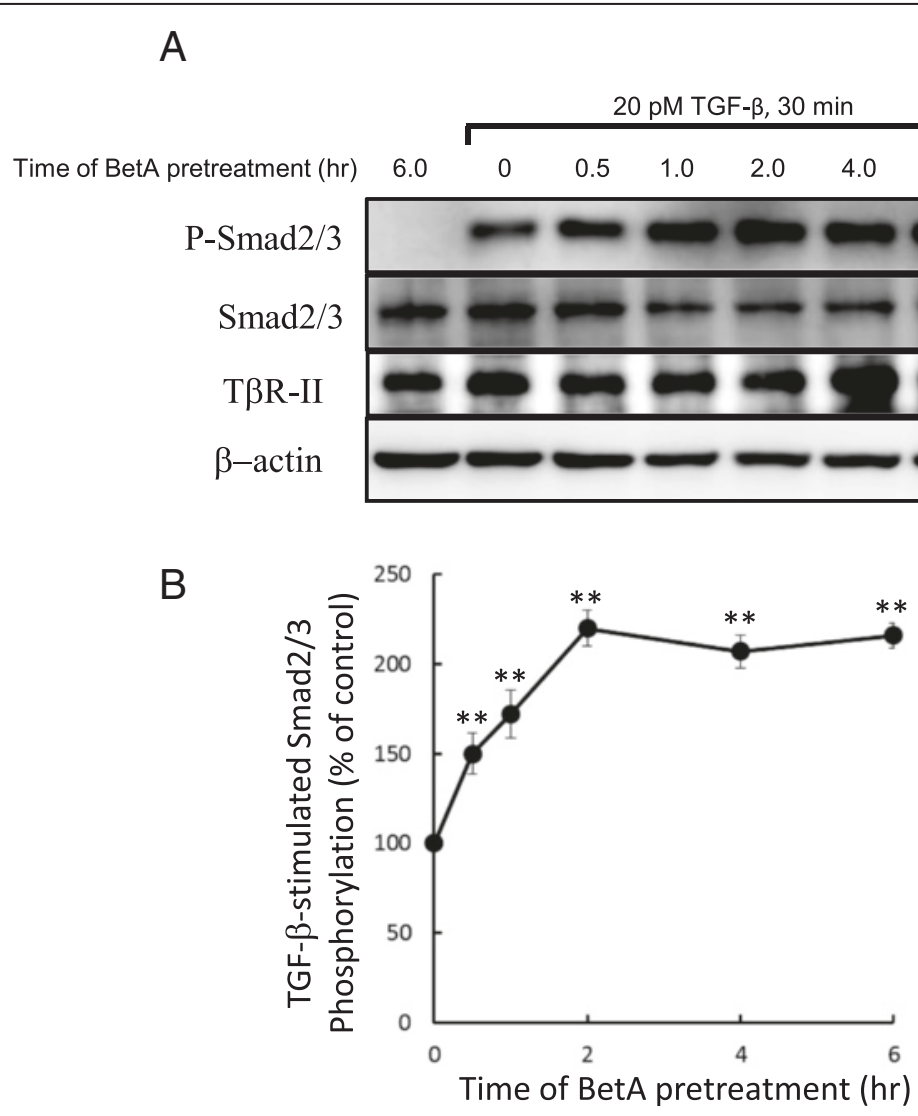

Fig. 4 BetA enhances TGF- $\beta$-induced Smad2 phosphorylation and nuclear translocation in Mv1Lu cells. Cells were pretreated with BetA, for 0, 0.5, 1, 2, 4, and 6 h, and then further incubated with 100 pM TGF- $\beta$ for 30 min. The P-Smad2 and total Smad2 levels in the cell lysates were analyzed by immunoblotting. The relative level of P-Smad2 (P-Smad2/Smad2) was estimated. A representation of 2 analyses is shown (a). The quantitative analysis of the immunoblots is shown (b). The relative level of P-Smad2 in cells treated only with TGF- $\beta$ was taken as $100 \%$ of TGF- $\beta$-stimulated Smad2 phosphorylation. The data from three different analyses represents the mean \pm SD. ${ }^{*}$ Significantly higher than that in cells treated with TGF- $\beta$ alone $(P<0.01)$ 
growth inhibition was assessed as the percentage of cell viability, where the vehicle-treated cells were considered $100 \%$ viable.

\section{Statistical analysis}

The data represent the means \pm standard deviation (SD). Group means were compared by one-way ANOVA (analysis of variance), followed by Tukey's procedure for multiple comparisons if necessary, using statistical software program SPSS ver. 17.0 for Windows (SPSS, Chicago, IL, USA). In all comparisons, a value of $\mathrm{p}<0.01$ was considered to indicate a statistically significant difference.

\section{Results}

BetA enhances TGF- $\beta$-induced transcriptional responsive The Mv1Lu cells were selected to examine the effect of BetA on TGF- $\beta$ signaling. The Mv1Lu cell is a model cell line for TGF- $\beta$ investigation, and exhibits a strong dosagedependent responsiveness to TGF- $\beta$, as determined by Mv1Lu cells stably expressing the luciferase reporter gene driven by the PAI- 1 promoter. TGF- $\beta$ (100 pM) induced luciferase activity by approximately 6 -fold in Mv1Lu cells (Fig. 2a). The TGF- $\beta$-dependent luciferase activity was enhanced by BetA treatment in a concentration-dependent manner, start with an approximate $20 \%$ increase in

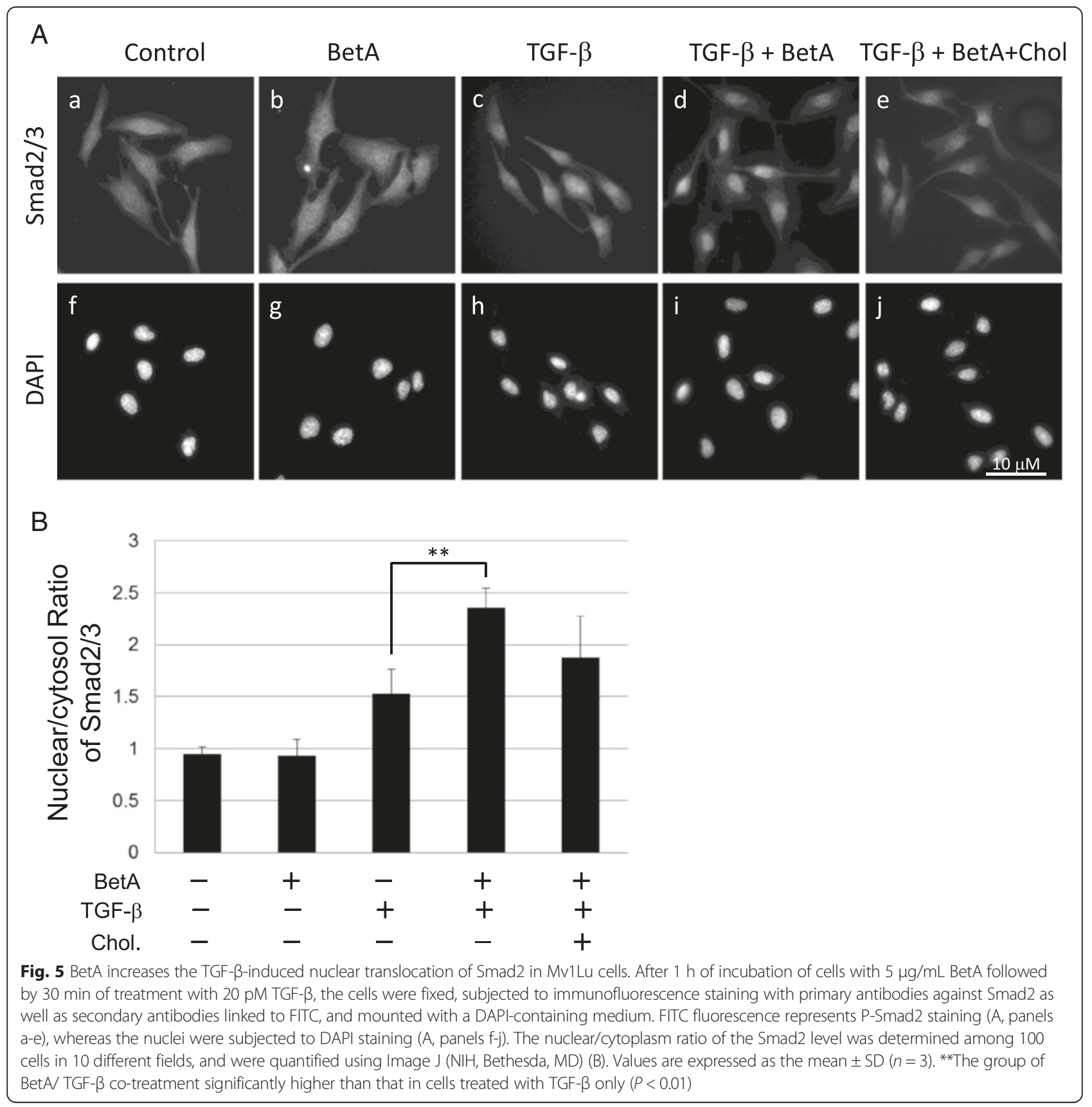


$0.5 \mu \mathrm{g} / \mathrm{mL}$ BetA-treated cells, and reaching roughly $60 \%$ at $5 \mu \mathrm{g} / \mathrm{mL}$ of BetA (Fig. 2b). The BetA also enhanced the TGF- $\beta$-induced transcriptional activation of fibronectin and collagen, as determined by transient transfection with the fibronectin and collagen luciferase promoter constructs (Fig. 2c and d, respectively). This study proposed that BetA enhances TGF- $\beta$ responsiveness by moving TGF- $\beta$ receptors out of the lipid raft microdomain in the plasma membrane. To find supporting evidence of this hypothesis, the cells were treated with $10 \mu \mathrm{g} / \mathrm{mL}$ or $20 \mu \mathrm{g} /$ $\mathrm{mL}$ of cholesterol, which has been reported as a critical component of lipid raft microdomains. Our previous reports have indicated that adding cholesterol to cultured cells could induce recruitment of TGF- $\beta$ receptors into the lipid raft membrane microdomain and facilitate receptor degradation $[17,18]$. As shown in Fig. 2, cholesterol prevented the BetA-enhanced transcriptional activation of PAI-1, fibronectin, and collagen induced by TGF- $\beta$ (Fig. 2b, c, and d, respectively). Cholesterol and BetA did not affect the basic reporter gene activity, indicating that the induced TGF- $\beta$ response was affected, not the luciferase activity or cellular activity itself. We did not observe any cell death from treatment with either BetA or cholesterol, as determined by MTT assay and trypan blue cell exclusion assays (data not shown). To further assess whether BetA acts on ligand binding and subsequent active receptor complex formation or on downstream TGF$\beta$ signaling, Mv1Lu cells were transiently transfected with caALK-5, which resulted in an 8-fold induction of PAI-1 promoter activity without TGF- $\beta$ stimulation (Fig. 3a). The BetA enhanced caALK-5-stimulated transcriptional activities, including PAI-1, fibronectin, and collagen

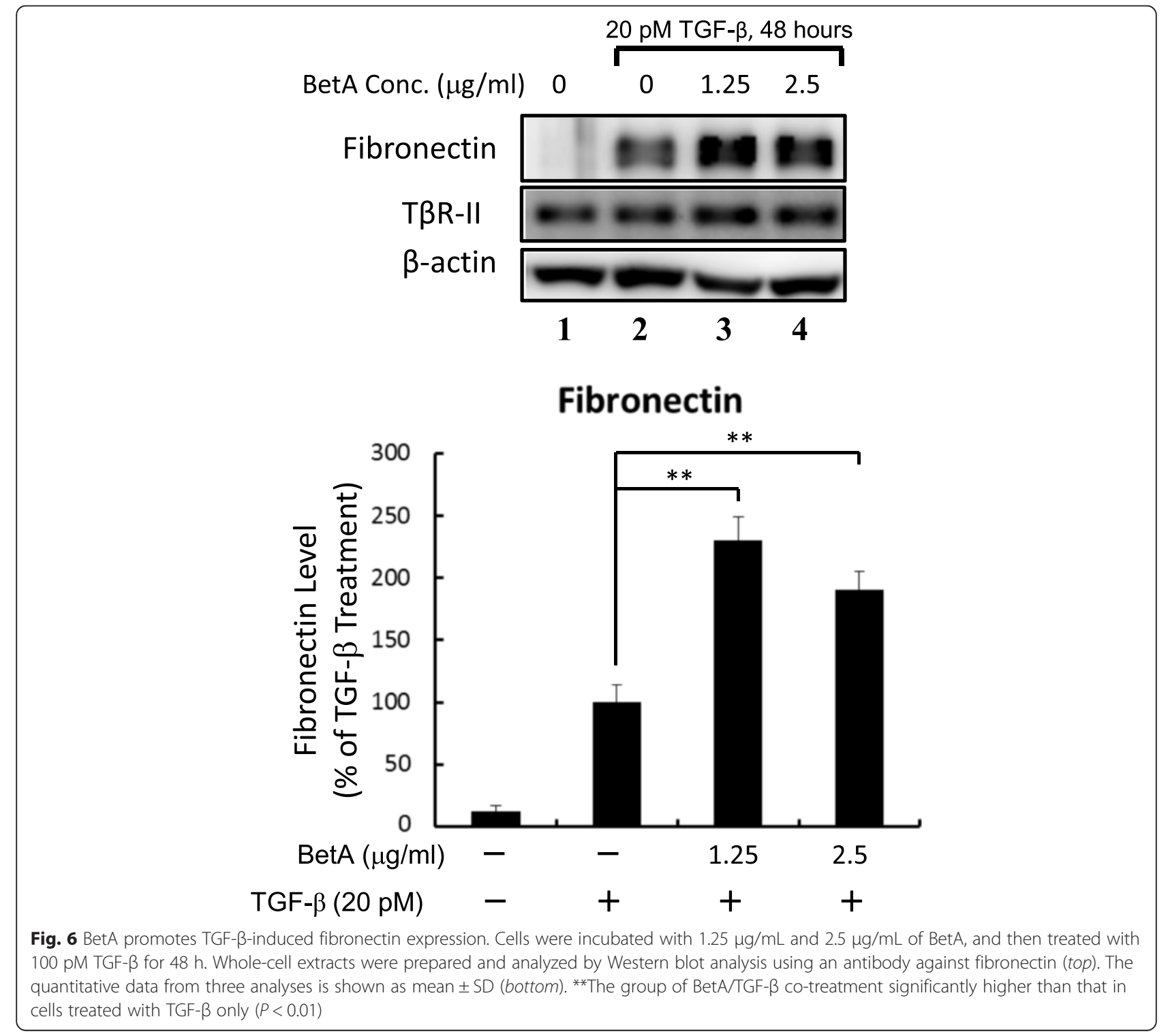


(Fig. 3b, c, and $\mathrm{d}$, respectively), in a concentrationdependent manner. Cholesterol treatment suppressed the BetA-specific luciferase activities exclusively, not the basal luciferase activities induced by caALK-5. This result implies that BetA and cholesterol affect the components of the TGF- $\beta$ receptor-Smad signaling pathway, rather than altering ligand binding to TGF- $\beta$ receptors.

\section{BetA enhances TGF- $\beta$-induced Smad2 phosphorylation and nuclear translocation}

Because cholesterol is a critical structural component of lipid rafts and caveolae [27, 28] and shares a similar chemical structure with BetA, treatment of cells with BetA may modulate TGF- $\beta$-stimulated signaling and cellular responses by altering the structure and function of lipid rafts/caveolae. To test the effect of BetA on TGF- $\beta$ induced signaling, we determined the effect of BetA treatment on TGF- $\beta$-stimulated Smad2 phosphorylation and nuclear translocation, both of which are key signaling events leading to TGF- $\beta$ responsiveness $[16,29,30]$. As shown in Fig. 4a and b, BetA effectively enhanced Smad 2 phosphorylation stimulated by TGF- $\beta$ in a timedependent manner in Mv1Lu cells. After $1 \mathrm{~h}$ of BetA pretreatment, Smad2 phosphorylation increased by $75 \%$. At $2 \mathrm{~h}$ of pretreatment, BetA enhanced Smad2 phosphorylation by over $100 \%$. To determine the effect of BetA on Smad2 nuclear translocation, we performed immunofluorescent staining using the anti-Smad2/3 antibody and nuclear 4',6-diamidine-2-phenylindole (DAPI) staining. As shown in Fig. 5A, BetA enhanced TGF- $\beta$-induced Smad2 nuclear translocation (Fig. 5Ad versus Fig. 5Ac). After counting the cells that underwent Smad2 nuclear localization from 3 separate experiments, we found that TGF- $\beta$-induced Smad2 nuclear translocation in all of the treated cells, whereas BetA enhanced Smad2 nuclear translocation in $70 \pm 5 \%$ of these cells (Fig. 5B). In the experiments with BetA alone and the vehicle $(0.01 \% \mathrm{EtOH})$, the cells did not exhibit any nuclear translocation (Figs. 5Aa and $\mathrm{Ab}$, respectively). Overall, these results imply that BetA treatment enhances TGF- $\beta 1$-induced signaling.

\section{TGF- $\beta 1$-induced fibronectin expression is promoted by BetA}

One biological activity of TGF- $\beta$ is the transcriptional activation of gene coding for extracellular matrix (ECM) proteins, which is a crucial event in wound healing, tissue repair, and cancer progression in adult tissue [31, 32]. During prolonged treatment, TGF- $\beta$ successively induces epithelial-mesenchymal transition differentiation with an increased expression of ECM proteins, including fibronectin in epithelial cells [33, 34]. This transcriptional activation is mediated by the $\mathrm{Smad} 2 / 3$ signaling pathway. To define the effect of BetA on TGF- $\beta$ responsiveness, we determined that of BetA on TGF- $\beta$-induced fibronectin expression in cells by using an ECL system for western blotting. As shown in Fig. 6, the treatment of Mv1Lu cells with BetA increased TGF- $\beta$-induced fibronectin expression: at $1.25 \mu \mathrm{g} / \mathrm{mL}$, BetA enhanced fibronectin expression by approximately $95 \%$ compared with TGF- $\beta$ alone (lane 3 versus lane 2) in Mv1Lu cells. At $2.5 \mu \mathrm{g} / \mathrm{mL}$ of BetA treatment, we found a slight

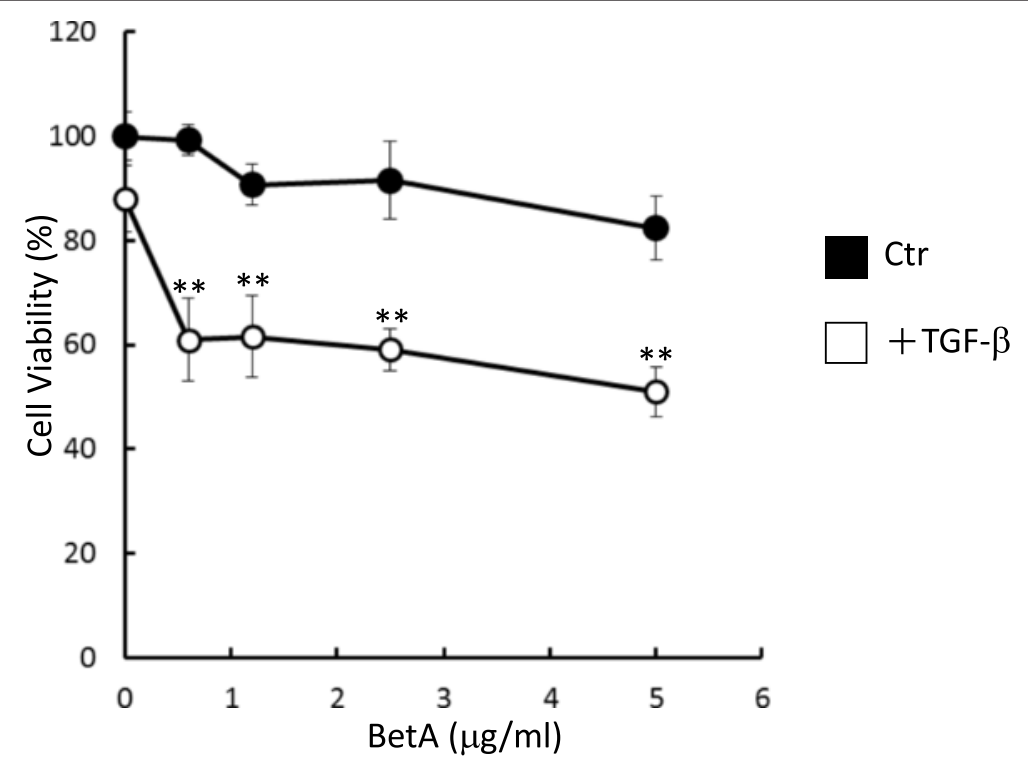

Fig. 7 BetA enhances TGF- $\beta$-induced cell death in Mv1Lu cells. Cells were pretreated with BetA for $4 \mathrm{~h}$ and stimulated with 20 pM of TGF- $\beta$ for $30 \mathrm{~h}$. The MTT (cell viability) assay showed that BetA enhanced TGF- $\beta$-induced cell death in a concentration-dependent manner after $30 \mathrm{~h}$ of exposure to BetA. Data represents the mean \pm SD $(n=3) .{ }^{*}$ Significantly lower than that in cells treated with TGF- $\beta$ alone $(P<0.01)$ 
decrease in fibronectin expression compared with $1.25 \mu \mathrm{g} / \mathrm{mL}$ of BetA treatment, which may be due to other effects from long-term BetA treatment.

\section{TGF- $\beta$-induced Mv1Lu cell growth inhibition is enhanced by BetA}

Another prominent biological activity of TGF- $\beta$ is the growth inhibition of numerous cell types $[12,16,30$, 35-37]. If BetA enhances TGF- $\beta$ responsiveness, it should augment TGF- $\beta$ growth inhibition, which is also mediated by the Smad2/3 signaling pathway. To verify this hypothesis, we pretreated Mv1Lu cells with increasing concentrations (as indicated) of BetA at $37{ }^{\circ} \mathrm{C}$ for $4 \mathrm{~h}$, and then further incubated them with $20 \mathrm{pM}$ TGF$\beta$ at $37{ }^{\circ} \mathrm{C}$ for $30 \mathrm{~h}$. In order to show the TGF- $\beta$-induced growth inhibition enhanced by BetA, we used a low concentration $(20 \mathrm{pM})$ of TGF- $\beta$ in these experiments. In the absence of BetA, 20 pM of TGF- $\beta$ inhibited Mv1Lu cell growth by approximately $10 \%$ (the first closed circle on the left side in Fig. 7). In the presence of BetA ( 0.6 to $5 \mu \mathrm{g} / \mathrm{mL})$, TGF- $\beta_{1}$-induced growth inhibition increased by $40 \%$ (the closed circles in Fig. 7). In this study, none of the BetA concentrations used affected cell growth and viability significantly (the open circles in Fig. 7). The control was treated with $0.01 \%$ EtOH without TGF- $\beta$ (the first open circle from the left side in Fig. 7).

\section{Bet $A$ increases TGF- $\beta$ receptor accumulation in the non-caveolae microdomain}

We previously reported that TGF- $\beta$ responsiveness is determined by the localization of T $\beta R-I$ and T $\beta R$-II in the lipid

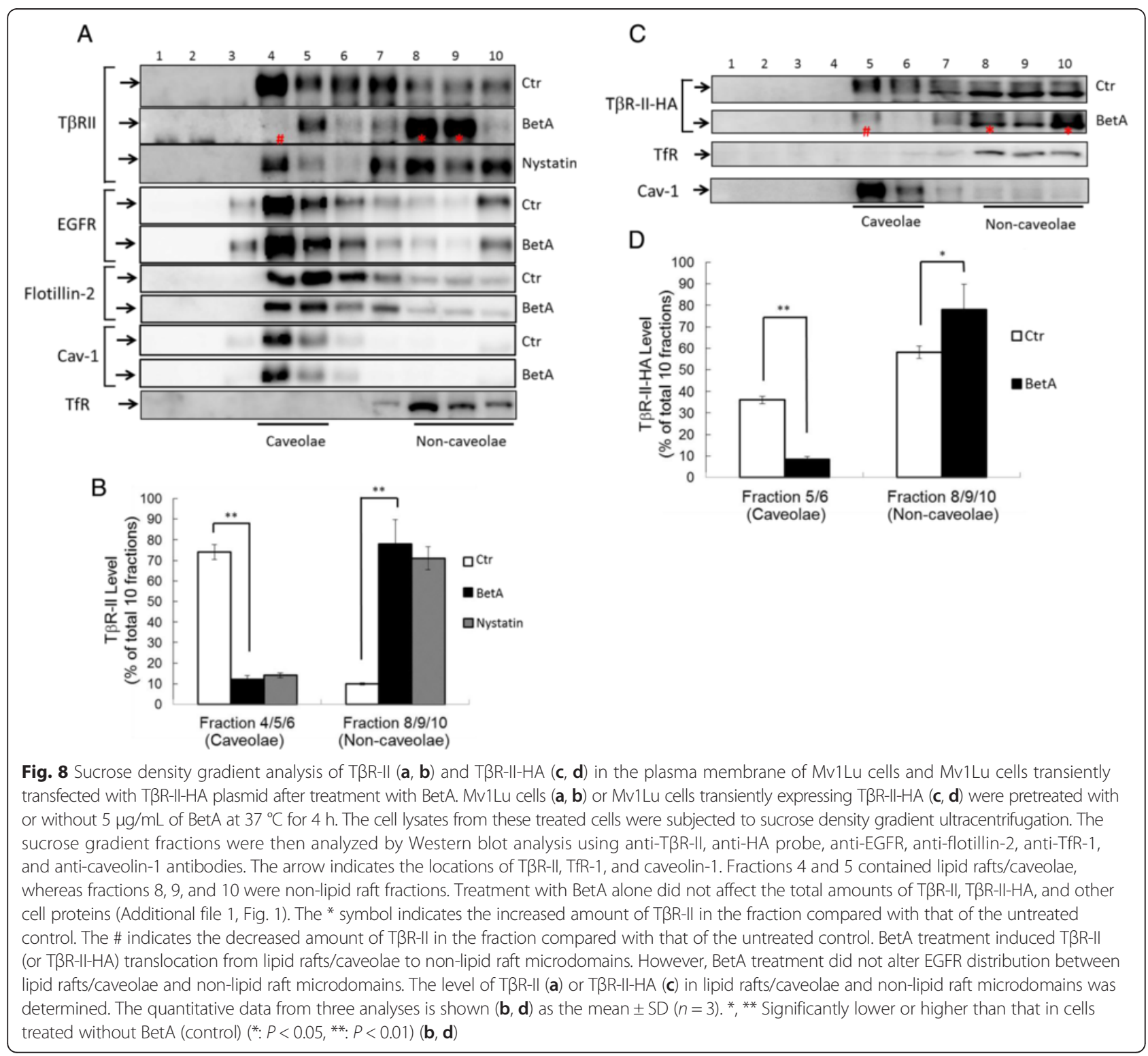


raft/caveolae and non-caveolae microdomains of the plasma membranes $[17-19,26]$. To test the effect of BetA on the plasma microdomain localization of TGF- $\beta$ receptors, we analyzed the lipid raft and non-lipid raft localization of T $\beta R$-II in the plasma membrane of untreated cells or cells treated with BetA $(5 \mu \mathrm{g} / \mathrm{mL})$ by conducting sucrose density gradient ultracentrifugation analysis followed by western blotting. As shown in Fig. 8a, T $\beta$ R-II was present in both the non-caveolae (fractions 8 to 10) and lipid raft/caveolae fractions (4 and 5), which contained transferrin receptor 1 (TfR-1) and caveolin-1, respectively. After BetA treatment, TBR-II was found to be enriched in the non-caveolae fractions ( 8 and 9) of the plasma membrane in Mv1Lu cells compared with the same fractions before BetA treatment (Fig. 8, BetA versus control). Treatment with nystatin, a cholesterol-depleting agent, also induced T $\beta$ R-II translocation from the lipid raft/caveolae to non-caveolae microdomain. We confirmed that BetA plays a similar role to nystatin in TGF- $\beta$ receptor translocation.
Both BetA and nystatin moved the TGF- $\beta$ receptor from fractions 4 and 5 (lipid raft) to fractions 8 to 10 (non-lipid raft) (Fig. 8a BetA versus nystatin). As shown in Fig. 8c, Mv1Lu cells transiently expressing HA-tagged T $\beta R$-II were incubated in control media or media containing $5 \mu \mathrm{g} / \mathrm{mL}$ of BetA, and were processed for sucrose gradient fractionation and western blotting with the anti-HA probe antibody. The BetA treatment induced T $\beta$ R-II-HA translocation from lipid raft to non-lipid raft microdomains. To test whether BetA changes the membrane localization of other types of growth factor receptors, we examined EGF receptor localization in BetA-treated cells. The BetA treatment did not alter the membrane localization of EGF receptors (Fig. 8a). To further test BetA-induced TGF- $\beta$ receptor translocation in the plasma membrane, Mv1Lu cells transiently expressing T $\beta$ R-II-HA were treated with or without BetA, and were analyzed trough immunofluorescence microscopy by using antibodies against HA-probe and caveolin-1. As shown in Fig. 9, in the control

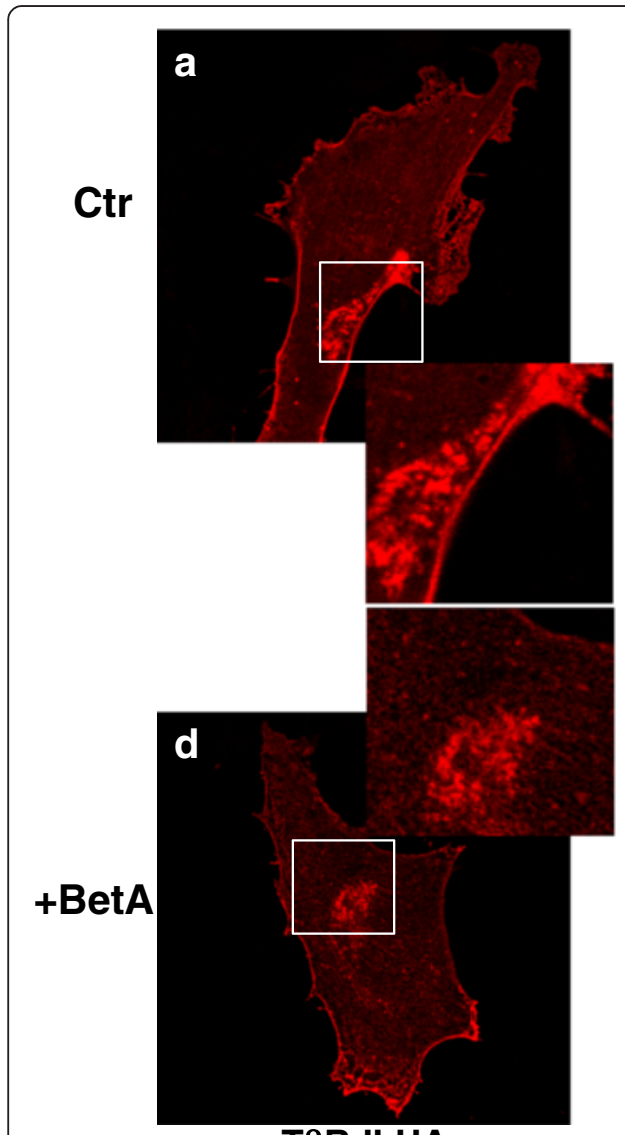

T $\beta$ R-II-HA

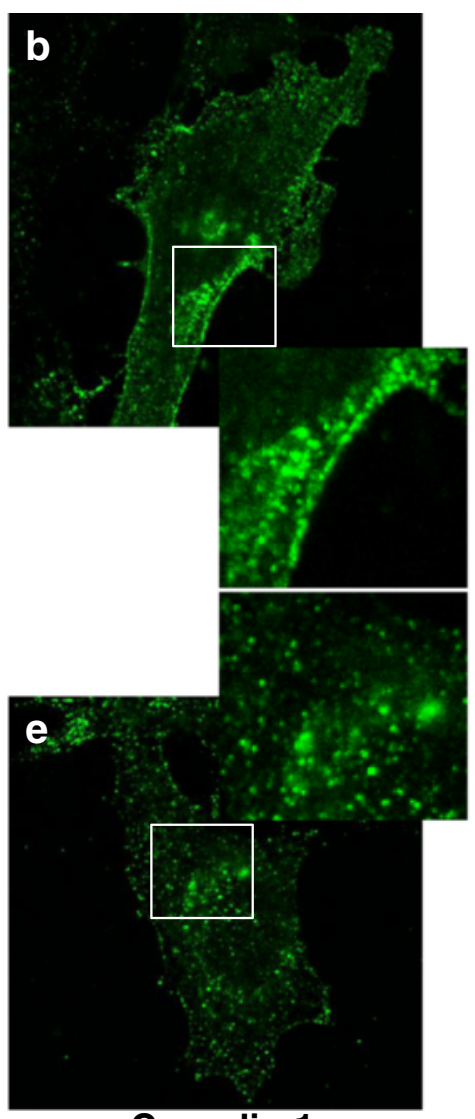

Caveolin-1

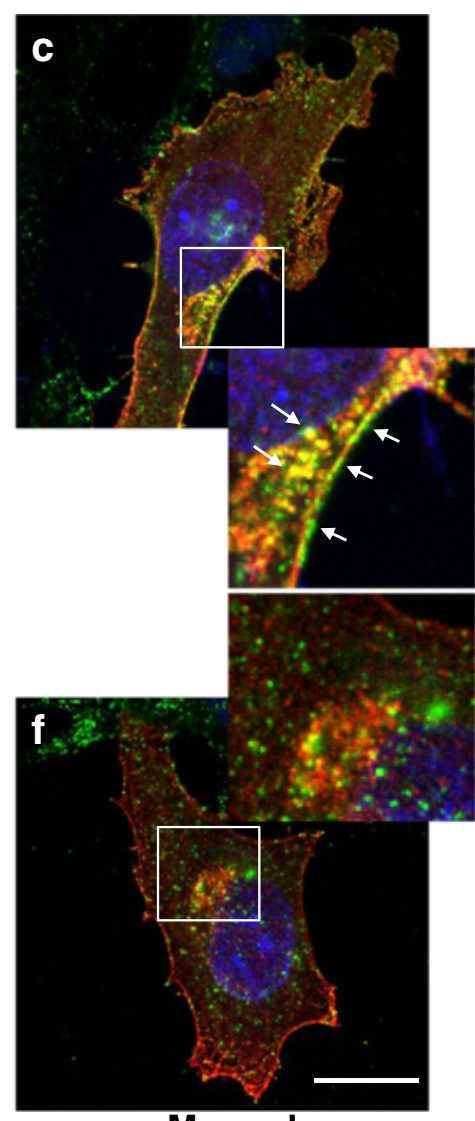

Merged

Fig. 9 The immunofluorescence localization of TRR-II-HA and caveolin-1 in Mv1Lu cells treated with and without BetA. The Mv1Lu cells transiently expressing TßR-II-HA were treated with or without $5 \mu \mathrm{g} / \mathrm{mL}$ of BetA at $37^{\circ} \mathrm{C}$ for $1 \mathrm{~h}$. The cells were then fixed with cold methanol and incubated with a mouse antibody against HA (panels $\mathbf{a}$ and $\mathbf{b}$ ) and a rabbit antibody against caveolin-1 (panels $\mathbf{b}$ and $\mathbf{e}$ ), followed by incubation with Rhodamine-conjugated donkey anti-mouse antibody or FITC-conjugated goat anti-rabbit antibody. Fluorescence in cells was examined using a confocal microscope: Bar, 20 um. The white arrows indicate the colocalization of TBR-II-HA and caveolin-1 at the cell surface and endocytic vesicle (panel $\mathbf{c}$, enlarged picture in lower right corner.) before BetA treatment. (panel f, enlarged picture in upper right corner.) BetA treatment reduces the colocalization of TRR-II-HA and caveolin-1 
experiment, T $\beta$ R-II-HA (depicted in red) and caveolin-1 (green) were colocalized and accumulated in lipid rafts (Fig. 9c). After 30 min of BetA treatment, BetA reduced the colocalization of TßR-II-HA and caveolin-1 (Fig. 9f). Combined with the findings shown in Figs. 8 and 9, these results imply that cell treatment with BetA and nystatin increased the accumulation of T $\beta R$-II in non-caveolae microdomains, and presumably increased endosomal signaling $[18,26,38]$, resulting in enhanced TGF- $\beta$ responsiveness.

\section{Discussion and conclusion}

Triterpenoids are studied extensively for their potential use as anticancer and antifibrotic agents [39-45], and BetA is one of the most promising compounds in this class. Several proteins and pathways are clearly targeted by BetA, but none of these individual targets provide a satisfactory and comprehensive view of the overall mechanism. The BetA compound has been shown to inhibit aminopeptidase $\mathrm{N}$, an enzyme involved in the regulation of angiogenesis that is overexpressed in several cancers [46, 47]. Moreover, one study demonstrated that BetA blocks the catalytic activity of topoisomerase I by abrogating the interaction of the enzyme and the DNA substrate [48]. Another important target is the NFkB pathway, a pro-inflammatory and prosurvival node in which a transcription factor regulates many cell cycle, differentiation, and apoptosis genes; this pathway is constitutively active in many human cancers $[49,50]$. The BetA suppresses NFkB activation by inhibiting ІкB $\alpha$ kinase and p65 phosphorylation [51]. Although

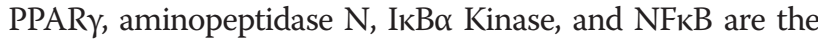
direct targets of BetA, they still cannot account for all of its known biological activities. Because BetA is similar to cholesterol in structure, it is tempting to speculate that BetA may be intercalated into lipid rafts and might modulate their membrane fluidity like other cholesterol derivatives [23]. However, BetA-induced apoptosis is not mediated by the Fas receptor, which is activated when membrane fluidity is increased after cellular exposure to methyl- $\beta$-cyclodextrin [52]. Suh et al. and Ji et al. have reported that synthesized triterpenoids synergize with TGF- $\beta$ to induce the expression of TGF $\beta$ receptors as well as the activity of the TGF- $\beta$-responsive plasminogen activator inhibitor-1 (PAI-1) promoter, prolong Smad phosphorylation and signaling, and activate the promoters of activin and BMP reporter constructs [53, 54]. However, despite all of these observations, an immediate, direct molecular target of triterpenoids in the TGF- $\beta$ network has yet to be identified [55]. Di Guglielmo et al. [38] and Chen et al. [18, 19, 26] have demonstrated that TGF- $\beta$ responsiveness is

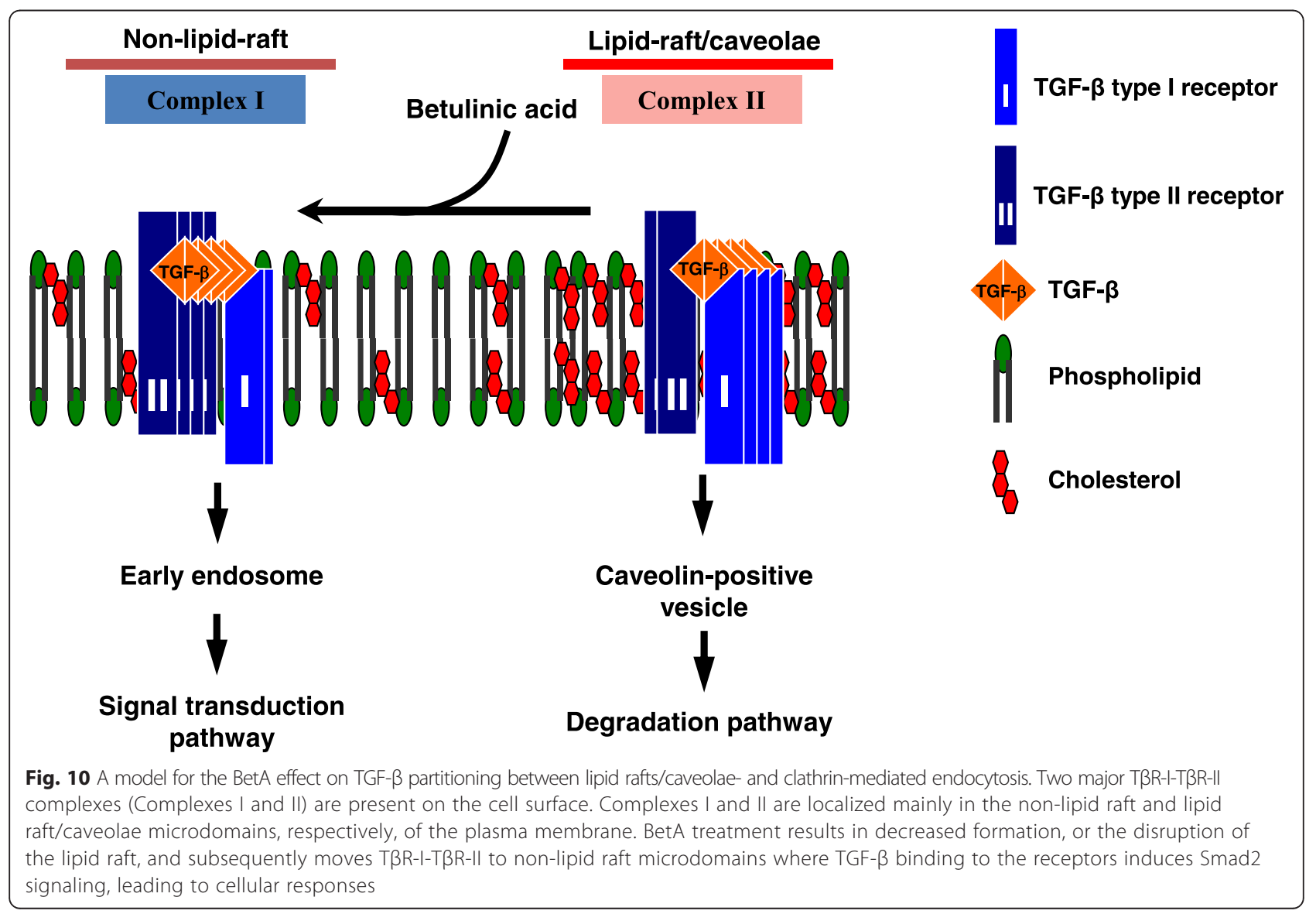


determined by TGF- $\beta$ receptor partitioning between lipid raft/caveolae-mediated and clathrin-mediated endocytosis. Lipid raft/caveolae-mediated endocytosis facilitates TGF- $\beta$ degradation, thereby suppressing TGF- $\beta$ responsiveness. By contrast, clathrin-mediated endocytosis results in Smad2/3-dependent endosomal signaling, thus promoting TGF- $\beta$ responsiveness. Based on the dominance model for the signal that controls TGF- $\beta$ partitioning between the 2 distinct endocytosis pathways $[18,19,26,36]$, to the best of our knowledge, this study is the first to propose that BetA increased TGF- $\beta$ responsiveness through lipid raft disruption and by pushing the TGF- $\beta$-TGF- $\beta$ receptor complex into the non-lipid raft microdomain in the plasma membrane. Several lines of evidence presented herein indicate that BetA is a TGF- $\beta$ receptor activator that can effectively enhance (Smad2/3-dependent) TGF- $\beta$ responsiveness in Mv1Lu cells: BetA treatment (1) enhances TGF- $\beta$ induced transcriptional activation such as PAI-1, fibronectin, and the collagen promoter, and these "BetA-specific" activations are antagonized by cholesterol treatment; (2) enhances TGF- $\beta$-induced signaling such as Smad2 phosphorylation and nuclear translocation; (3) increases TGF- $\beta$-induced fibronectin expression in Mv1Lu cells; (4) augments TGF- $\beta$-induced growth inhibition in Mv1Lu cells; and (5) most important, the effect of BetA on TGF- $\beta$ responsiveness is rapid and coordinates with BetA-induced TGF- $\beta$ receptor translocation from lipid $\mathrm{raft} /$ caveolae to non-caveolae on the plasma membrane. The effect starts from $30 \mathrm{~min}$ after the incubation of BetA-treated cells, and reaches its maximum effect at $2 \mathrm{~h}$ (unpublished results). In this study, we demonstrated that BetA treatment increases the accumulation of T $\beta R$-I and T $\beta R$-II to non-lipid rafts/non-caveolae (as Complex I) (Fig. 10), resulting in enhanced TGF- $\beta$ responsiveness. The depletion of cholesterol from the plasma membrane by cholesterol-depleting agents (e.g., nystatin) leads to a decreased formation or destabilization of lipid rafts/caveolae, thereby also increasing the localization of T $\beta R-I$ and T $\beta R$-II (as Complex I) in nonlipid raft microdomains (Fig. 8a). It is possible that a number of these activities are mediated by their ability to affect the structure and function of lipid rafts/caveolae, which are known to modulate signaling mediated by $G$ protein-coupled receptors, receptor tyrosine kinases (EGFR), TGF- $\beta$ receptors (T $\beta R-I$ and T $\beta R-I I)$, and possibly others $[21,26,38,56-58]$. However, in the present study, EGFR membrane microdomain localization remained unchanged after BetA treatment. These results implicate the specificity of BetA treatment in TGF- $\beta$ responsiveness. In conclusion, this is the first report to show that BetA augments TGF- $\beta$ signaling by shifting TGF- $\beta$ receptors from the lipid raft/caveolae to non-caveolae microdomain in the plasma membrane.

\section{Additional file}

Additional file 1: Figure S1. The treatment of BetA does not change the levels of T $\beta R-I I, T \beta R-I I$, and caveolin-1 in Mv1Lu cells. Figure S2. SB431542 inhibits BetA-enhanced TGF- $\beta$-induced fibronectin expression in Mv1Lu cells. (PDF 325 kb)

\begin{abstract}
Abbreviations
TGF- $\beta$ : transforming growth factor-beta; BetA: betulinic acid

(3b, hydroxy-lup-20(29)-en-28-oic acid); TfR: transferrin receptor; EEA1: early endosome antigen 1; T $\beta R$-I: type I TGF- $\beta$ receptor; T $\beta$ R-II: type II TGF- $\beta$ receptor; PAI-1: plasminogen activator inhibitor-1; Mv1Lu cell: mink lung epithelial cell; ALK-5: activin receptor-like kinase; MTT: (3-[4,5-dimethylthiazol-2-yl]-2,5diphenyl tetrazoliumbromide); ECL: enhanced chemiluminescence; NFKB: nuclear factor kappa-light-chain-enhancer of activated B cells; PPARY: peroxisome proliferator-activated receptor gamma; IKBa: nuclear factor of kappa light polypeptide gene enhancer in B-cells inhibitor-alpha.
\end{abstract}

\section{Competing interest}

The authors declare that they have no competing interests.

\section{Authors' contributions}

$C Y, Y P$, and MW performed the research. YB, DC, CY, and $H T$ contributed essential reagents or tools. $C Y, Y P$, and $C L$ analyzed the data. $C L$ designed the research study and wrote the paper. All authors read and approved the final manuscript.

\section{Acknowledgements}

This work is supported by the National Science Council of Taiwan (101-2320-B-110-003, 102-2320-B-110-007, 103-2314-B-037-064, and 103-2320-B-037-014), KMU Center for Stem Cell Research (KMU-TP103G01, KMU-TP103G00, KMU-TP103G03, KMU-TP103G04 \& KMU-TP103G05), VGH-NSYSU Joint Research Project (VGHNSU103-004), and NSYSU-KMU Joint Research Project (NSYSUKMU2013-1006).

\section{Author details}

${ }^{1}$ Department of Biological Science, National Sun Yat-sen University, Kaohsiung 804Taiwan, ROC. ${ }^{2}$ Doctoral Degree Program in Marine Biotechnology, National Sun Yat-sen University and Academia Sinica, Kaohsiung 804Taiwan, ROC. ${ }^{3}$ Graduate Institute of Clinical Pharmacy, College of Pharmacy, Kaohsiung Medical University, Kaohsiung 807Taiwan, ROC. ${ }^{4}$ Division of Gastroenterology, Department of Internal Medicine, Kaohsiung Medical University Hospital, Kaohsiung 807Taiwan, ROC. ${ }^{5}$ Center for Stem Cell Research, Kaohsiung Medical University, Kaohsiung 807Taiwan, ROC. ${ }^{6}$ Division of Pathology, Department of Internal Medicine, Kaohsiung Medical University Hospital, Kaohsiung 807Taiwan, ROC. ${ }^{7}$ Taiwan Ocean Research Institute, National Applied Research Laboratories, Kaohsiung 852Taiwan, ROC.

Received: 1 July 2015 Accepted: 12 January 2016

Published online: 27 February 2016

\section{References}

1. Fulda S, Friesen C, Los M, Krammer PH, Peter ME, Debatin KM. Betulinic acid triggers CD95 (APO-1/Fas)- and p53-independent apoptosis via activation of caspases in neuroectodermal tumors. Cancer Res. 1997;57:4956-64.

2. Alakurtti S, Makela T, Koskimies S, Yli-Kauhaluoma J. Pharmacological properties of the ubiquitous natural product betulin. Eur J Pharm Sci. 2006;29:1-13.

3. Kasperczyk H, La Ferla-Bruhl K, Zwacka RM, Debatin KM, Fulda S. Betulinic acid as new activator of NF-kappaB: molecular mechanisms and implications for cancer therapy. Oncogene. 2005;24:6945-56.

4. Damle AA, Pawar YP, Narkar AA. Anticancer activity of betulinic acid on MCF-7 tumors in nude mice. Indian J Exp Biol. 2013;51:485-91.

5. Kessler JH, Mullauer FB, de Roo GM, Medema JP. Broad in vitro efficacy of plant-derived betulinic acid against cell lines derived from the most prevalent human cancer types. Cancer Lett. 2007;251:132-45.

6. Mukherjee R, Jaggi M, Rajendran P, Srivastava SK, Vardhan A, Burman AC Betulinic acid and its derivatives as anti-angiogenic agents. Bioorg Med Chem Lett. 2004;14:2181-4.

7. Fulda S, Scaffidi C, Susin SA, Peter ME, Debatin KM. Activation of mitochondria and release of mitochondrial apoptogenic factors by betulinic acid. J Biol Chem. 1998;273:33942-8. 
8. Fulda S, Sieverts H, Friesen C, Herr I, Debatin KM. The CD95 (APO-1/Fas) system mediates drug-induced apoptosis in neuroblastoma cells. Cancer Res. 1997;57:3823-9.

9. Bierie B, Moses HL. Tumour microenvironment: TGFbeta: the molecular Jekyll and Hyde of cancer. Nat Rev Cancer. 2006;6:506-20.

10. Letterio JJ. TGF-beta signaling in T cells: roles in lymphoid and epithelial neoplasia. Oncogene. 2005;24:5701-12.

11. Massague J, Cheifetz S, Boyd FT, Andres JL. TGF-beta receptors and TGF-beta binding proteoglycans: recent progress in identifying their functional properties. Ann N Y Acad Sci. 1990;593:59-72.

12. Roberts AB. Molecular and cell biology of TGF-beta. Miner Electrolyte Metab. 1998;24:111-9.

13. Derynck R, Akhurst RJ, Balmain A. TGF-beta signaling in tumor suppression and cancer progression. Nat Genet. 2001;29:117-29.

14. Trapani JA. The dual adverse effects of TGF-beta secretion on tumor progression. Cancer Cell. 2005;8:349-50.

15. Ostroukhova M, Qi Z, Oriss TB, Dixon-McCarthy B, Ray P, Ray A. Tregmediated immunosuppression involves activation of the Notch-HES1 axis by membrane-bound TGF-beta. J Clin Invest. 2006;116:996-1004.

16. Heldin CH, Miyazono K, ten Dijke P. TGF-beta signalling from cell membrane to nucleus through SMAD proteins. Nature. 1997;390:465-71.

17. Chen CL, Huang SS, Huang JS. Cholesterol modulates cellular TGF-beta responsiveness by altering TGF-beta binding to TGF-beta receptors. J Cell Physiol. 2008;215:223-33.

18. Chen CL, Liu IH, Fliesler SJ, Han X, Huang SS, Huang JS. Cholesterol suppresses cellular TGF-beta responsiveness: implications in atherogenesis. J Cell Sci. 2007; 120:3509-21.

19. Chen CL, Tetri LH, Neuschwander-Tetri BA, Huang SS, Huang JS. A mechanism by which dietary trans fats cause atherosclerosis. J Nutr Biochem. 2011;22:649-55.

20. Muriel O, Echarri A, Hellriegel C, Pavon DM, Beccari L, Del Pozo MA. Phosphorylated filamin A regulates actin-linked caveolae dynamics. J Cell Sci. 2011;124:2763-76

21. Simons K, Toomre D. Lipid rafts and signal transduction. Nat Rev Mol Cell Biol. 2000;1:31-9.

22. Sundivakkam PC, Kwiatek AM, Sharma TT, Minshall RD, Malik AB, Tiruppathi $C$ Caveolin-1 scaffold domain interacts with TRPC1 and IP3R3 to regulate Ca2+ store release-induced Ca2+ entry in endothelial cells. Am J Physiol Cell Physiol. 2009;296:C403-413

23. Yi JS, Choo HJ, Cho BR, Kim HM, Ko YG. Ginsenoside Rh2 induces ligand-independent Fas activation via lipid raft disruption. Biochem Biophys Res Commun. 2009;385:154-9.

24. Piek E, Ju WJ, Deng C, Kucherlapati R, Bottinger EP, Roberts AB. Functional characterization of transforming growth factor beta signaling in Smad2- and Smad3-deficient fibroblasts. J Biol Chem. 2001;276:19945-53.

25. Poncelet AC, de Caestecker MP, Schnaper HW. The transforming growth factor-beta/SMAD signaling pathway is present and functional in human mesangial cells. Kidney Int. 1999;56:1354-65.

26. Chen CL, Huang SS, Huang JS. Cellular heparan sulfate negatively modulates transforming growth factor-beta1 (TGF-beta1) responsiveness in epithelial cells. J Biol Chem. 2006;281:11506-14.

27. Park DS, Cohen AW, Weiss LM, Tanowitz HB, Lisanti MP. Caveolin-1 null (-/-) mice show dramatic reductions in life span. Biochemistry. 2003;42:15124-31.

28. Pike LJ. Lipid rafts: bringing order to chaos. J Lipid Res. 2003;44:655-67.

29. Kretzschmar M, Massague J. SMADs: mediators and regulators of TGF-beta signaling. Curr Opin Genet Dev. 1998;8:103-11.

30. Moustakas A, Souchelnytskyi S, Heldin CH. Smad regulation in TGF-beta signal transduction. J Cell Sci. 2001;114:4359-69.

31. Thiery JP, Acloque H, Huang RY, Nieto MA. Epithelial-mesenchymal transitions in development and disease. Cell. 2009;139:871-90.

32. Miyazono K. Transforming growth factor-beta signaling in epithelialmesenchymal transition and progression of cancer. Proc Jpn Acad Ser B Phys Biol Sci. 2009:85:314-23.

33. Shirakihara T, Horiguchi K, Miyazawa K, Morita I, Miyazono K, Saitoh M. TGF-beta regulates isoform switching of FGF receptors and epithelial-mesenchymal transition. EMBO J. 2011;30:783-95.

34. Shirakihara T, Kawasaki T, Miyazono K, Miyazawa K, Saitoh M. Identification of integrin alpha3 as a molecular marker of cells undergoing epithelialmesenchymal transition and of cancer cells with aggressive phenotypes. Cancer Sci. 2013;104:1189-97.
35. Hocevar BA, Howe PH. Mechanisms of TGF-beta-induced cell cycle arrest. Miner Electrolyte Metab. 1998;24:131-5.

36. Huang SS, Huang JS. TGF-beta control of cell proliferation. J Cell Biochem. 2005:96:447-62

37. Laiho M, DeCaprio JA, Ludlow JW, Livingston DM, Massague J. Growth inhibition by TGF-beta linked to suppression of retinoblastoma protein phosphorylation. Cell. 1990;62:175-85.

38. Di Guglielmo GM, Le Roy C, Goodfellow AF, Wrana JL. Distinct endocytic pathways regulate TGF-beta receptor signalling and turnover. Nat Cell Biol. 2003;5:410-21.

39. Lin KW, Huang AM, Lin CC, Hour TC, Pu YS, Lin CN. Anti-cancer effects of ursane triterpenoid as a single agent and in combination with cisplatin in bladder cancer. Eur J Pharmacol. 2014:740:742-51.

40. Deeb D, Gao X, Liu YB, Pindolia K, Gautam SC. Pristimerin, a quinonemethide triterpenoid, induces apoptosis in pancreatic cancer cells through the inhibition of pro-survival Akt/NF-kappaB/mTOR signaling proteins and anti-apoptotic BCl-2. Int J Oncol. 2014:44:1707-15.

41. Swain SS, Rout KK, Chand PK. Production of triterpenoid anti-cancer compound taraxerol in Agrobacterium-transformed root cultures of butterfly pea (Clitoria ternatea L.). Appl Biochem Biotechnol. 2012:168:487-503.

42. Lavhale MS, Kumar S, Mishra SH, Sitasawad SL. A novel triterpenoid isolated from the root bark of Ailanthus excelsa Roxb (Tree of Heaven), AECHL-1 as a potential anti-cancer agent. PLoS One. 2009;4:e5365.

43. Aminzadeh MA, Reisman SA, Vaziri ND, Khazaeli M, Yuan J, Meyer CJ. The synthetic triterpenoid RTA dh404 (CDDO-dhTFEA) restores Nrf2 activity and attenuates oxidative stress, inflammation, and fibrosis in rats with chronic kidney disease. Xenobiotica. 2014;44:570-8.

44. Kulkarni AA, Thatcher TH, Morrissette J, Wright TW, Phipps RP, Sime PJ. The triterpenoid CDDO-Me inhibits bleomycin-induced lung inflammation and fibrosis. PLoS One. 2013;8:e63798.

45. Wei J, Zhu H, Tamaki Z, Hinchcliff M, Distler JH, Varga J. A synthetic PPAR-gamma agonist triterpenoid ameliorates experimental fibrosis: PPAR-gamma-independent suppression of fibrotic responses. Ann Rheum Dis. 2014;73:446-54.

46. Kwon HJ, Shim JS, Kim JH, Cho HY, Kim SH, Yu J. Betulinic acid inhibits growth factor-induced in vitro angiogenesis via the modulation of mitochondrial function in endothelial cells. Jpn J Cancer Res. 2002;93:417-25.

47. Melzig MF, Bormann $\mathrm{H}$. Betulinic acid inhibits aminopeptidase $\mathrm{N}$ activity. Planta Med. 1998;64:655-7.

48. Chowdhury AR, Mandal S, Mittra B, Sharma S, Mukhopadhyay S, Majumder HK. Betulinic acid, a potent inhibitor of eukaryotic topoisomerase I: identification of the inhibitory step, the major functional group responsible and development of more potent derivatives. Med Sci Monit. 2002:8:BR254-265.

49. Karin M, Greten FR. NF-kappaB: linking inflammation and immunity to cancer development and progression. Nat Rev Immunol. 2005:5:749-59.

50. Luo JL, Kamata H, Karin M. IKK/NF-kappaB signaling: balancing life and death-a new approach to cancer therapy. J Clin Invest. 2005;115:2625-32.

51. Takada Y, Aggarwal BB. Betulinic acid suppresses carcinogen-induced NFkappa B activation through inhibition of I kappa B alpha kinase and p65 phosphorylation: abrogation of cyclooxygenase-2 and matrix metalloprotease-9. J Immunol. 2003;171:3278-86.

52. Fulda S, Debatin KM. Sensitization for anticancer drug-induced apoptosis by betulinic acid. Neoplasia. 2005;7:162-70.

53. Ji Y, Lee HJ, Goodman C, Liby K, Sporn M, Suh N. The synthetic triterpenoid CDDO-imidazolide induces monocytic differentiation by activating the Smad and ERK signaling pathways in HL60 leukemia cells. Mol Cancer Ther. 2006;5:1452-8.

54. Suh N, Roberts AB, Birkey Reffey S, Miyazono K, Itoh S, ten Dijke P, et al. Synthetic triterpenoids enhance transforming growth factor beta/Smad signaling. Cancer Res. 2003:63:1371-6.

55. Liby KT, Yore MM, Sporn MB. Triterpenoids and rexinoids as multifunctional agents for the prevention and treatment of cancer. Nat Rev Cancer. 2007:7:357-69.

56. Galbiati F, Razani B, Lisanti MP. Emerging themes in lipid rafts and caveolae. Cell. 2001;106:403-11.

57. Gomez-Mouton C, Lacalle RA, Barber DF, Carrera AC, Martinez AC, Manes S. Dynamic redistribution of raft domains as an organizing platform for signaling during cell chemotaxis. J Cell Biol. 2004;164:759-68.

58. Le Roy C, Wrana JL. Clathrin- and non-clathrin-mediated endocytic regulation of cell signalling. Nat Rev Mol Cell Biol. 2005;6:112-26. 